\title{
The leukaemic phase of non-Hodgkin's lymphoma
}

\author{
B J Bain, D Catovsky
}

\section{Introduction}

Non-Hodgkin's lymphomas differ from chronic lymphoid leukaemias in that the major or primary site of disease is usually lymph nodes and other lymphoid tissues rather than the peripheral blood and bone marrow. However, it has long been recognised that lymphomas, like leukaemias, can have bone marrow infiltration and neoplastic cells can circulate in the peripheral blood. For this, the designation "lymphosarcoma cell leukaemia" was coined. When there are circulating lymphoma cells, diagnostic confusion with chronic lymphocytic leukaemia (CLL) and other lymphoid leukaemias can occur. Such cells may be present at diagnosis or may appear with disease progression. The likelihood of a leukaemic phase differs between different histological categories of lymphoma. If lymphoblastic and Burkitt's lymphomas are excepted, it is much more common with low grade than with high grade lymphomas.

The presence of circulating lymphoma cells may be the feature which leads to a diagnosis of non-Hodgkin's lymphoma. Although diagnosis of this group of disorders is based predominantly on histological examination of tissues, the cytology and immunophenotype can suggest a specific diagnosis which in some cases can be confirmed by cytogenetic or molecular genetic analysis performed on the circulating lymphoma cells. The detection of circulating lymphoma cells may also have prognostic significance, particularly in high grade lymphomas.

We shall discuss here the leukaemic phase of different subtypes of lymphoma using the disease classification and terminologies of the Kiel classification of non-Hodgkin's lymph$\mathrm{oma}^{1}$ and the French-American-British (FAB) classification of the chronic lymphoid leukaemias. $^{2}$

\footnotetext{
Department of Haematology, St Mary's Hospital Medical School, Norfolk Place, Paddington, London W2 1PG B J Bain D Catovsky

Correspondence to: Dr B J Bain.

Accepted for publication 10 October 1994
} includes CLL and lymphocytic lymphoma. Differentiating between these two conditions can be problematic, particularly for the histopathologist, as the lymph node biopsy specimens are indistinguishable. Clinical features do differ and it appears that these are two distinct diseases, although closely related. Cases are usually classified at CLL if there is peripheral blood lymphocytosis at presentation and as lymphocytic lymphoma if there is not. If these diagnostic criteria are used then, by definition, a case presenting in leukaemic phase is not lymphocytic lymphoma. ${ }^{34}$ If, however, the diagnosis is made on the basis of clinical features and cytology, then some cases may be recognised with leukaemic manifestations at presentation. ${ }^{5}$ The majority of patients with lymphocytic lymphoma never develop a leukaemic phase but a minority do so during the course of the disease, usually in the first few years after diagnosis (table 1) ${ }^{34}$ The leukaemic cells are cytologically very similar to those of CLL. The immunophenotype is also similar and trisomy 12 can occur in both conditions. There is no apparent difference in prognosis in those cases in which a leukaemic phase develops.

\section{SPLENIC LYMPHOMA WITH VILLOUS}

\section{LYMPHOCYTES}

Splenic lymphoma with villous lymphocytes (SLVL) is a haematologically distinctive condition, the characteristic histological features of which have recently been recognised. ${ }^{20}$ Variable numbers of circulating lymphoma cells are present in all recognised cases while the bone marrow is infiltrated in the great majority of cases. The lymphocyte count is usually only moderately elevated. The neoplastic cells are small mature lymphocytes with a variable amount of cytoplasm and, in about half the cases, a small nucleolus. Some have irregular protrusions or "villi", often at one pole of the cell. Others show plasmacytoid features. The blood film in SLVL may be confused with that of CLL but a distinction is readily made by immunophenotyping (table 2). ${ }^{21}$ Cytogenetic or molecular genetic (DNA) analysis can also support a diagnosis of SLVL as the $t(11$; 14)(q13;q32) translocation and the consequent juxtaposition of $b c l-1$ and the immunoglobulin heavy chain gene, which are common in mantle cell lymphoma, also occur in about $20 \%$ of cases of SLVL. Translocations with $2 \mathrm{p} 11$ and $7 \mathrm{q} 22$ breakpoints are also common whereas trisomy 12 and $13 q 14$ breakpoints, which are common in CLL, are rare in SLVL. ${ }^{22}$ 
Table 1 Percentage of cases of B cell lineage non-Hodgkin's lymphoma showing peripheral blood and bone marrow involvement

\begin{tabular}{|c|c|c|c|}
\hline \multirow[b]{2}{*}{ Type of lymphoma } & \multirow[b]{2}{*}{$\begin{array}{l}\text { Bone marrow } \\
\text { involvement }\end{array}$} & \multicolumn{2}{|c|}{ Peripheral blood involvement } \\
\hline & & At presentation & $\begin{array}{l}\text { At any time during the } \\
\text { course of the disease }\end{array}$ \\
\hline $\begin{array}{l}\text { Lymphocytic }^{34} \\
\text { SLVL } \\
\text { Immunocytoma }^{6-8} \\
\text { Follicular }^{579-11} \\
\text { Mantle cell }^{12-18} \\
\text { Monocytoid B cell } \\
\text { Centroblastic }^{7} \\
\text { Immunoblastic }^{7}\end{array}$ & $\begin{array}{l}52 \\
>80 \\
63 \\
35 \\
59 \\
38 \\
16 \\
28\end{array}$ & $\begin{array}{l}\text { Nil } \\
\text { All } \\
4-61 \\
14 \\
26 \\
\text { Rare } \\
2 \\
\text { Rare }\end{array}$ & $\begin{array}{l}\text { Nil } \\
\text { All } \\
6 \\
27 \\
\text { Not known } \\
3 \\
3 \\
\text { Rare }\end{array}$ \\
\hline
\end{tabular}

\section{LYMPHOPLASMACYTIC/LYMPHOPLASMACYTOID LYMPHOMA (IMMUNOCYTOMA)}

Lymphoplasmacytic and lymphoplasmacytoid lymphomas are lymphomas of small lymphocytes showing differentiation to plasma cells and to plasmacytoid lymphocytes, respectively. The term immunocytoma includes both subtypes. The frequency with which circulating lymphoma cells are recognised is higher in lymphoplasmacytoid than in lymphoplasmacytic lymphoma but varies greatly between reported series (table 1) ${ }^{6-8}$ The bone marrow is more frequently involved than the peripheral blood. Neoplastic cells vary from mature small lymphocytes, similar to those of CLL, to plasmacytoid lymphocytes and, in some cases, mature plasma cells. Cells sometimes contain globular inclusions or crystals. High counts are not common. The differential diagnosis is with CLL and with SLVL. Immunocytoma is distinguished from SLVL on the basis of cytological features. Lymphoplasmacytic lymphoma is distinguished from CLL on the basis of cytology and immunophenotype. Its immunophenotype is similar to that of other nonHodgkin's lymphomas and there may also be expression of some antigens typical of plasma cells such as CD38, CD25 and CD71. ${ }^{3}$ However, some cases described as lymphoplasmacytoid lymphoma differ little from CLL in either cytological features or immunophenotype; they may express CD5 and have trisomy 12. The distinction is made on the basis of cytology, by recognition of the subtle plasmacytoid features. No cytogenetic abnormalities sufficiently characteristic to confirm a diagnosis of immunocytoma have been identified as yet.

\section{CENTROBLASTIC/CENTROCYTIC (FOLLICULAR)} LYMPHOMA

In the great majority of cases of centroblastic/ centrocytic lymphoma the growth pattern is

Table 2 Immunophenotype of B-CLL and of B cell lymphomas in leukaemic phase

\begin{tabular}{llllll}
\hline Immunophenotype & CLL & SLVL & $F L$ & $M C L$ & $L C L$ \\
\hline SmIg & Weak & Strong & Strong & Strong & Strong \\
CD5 & ++ & $-l+$ & $-1+$ & + & $-/+$ \\
CD23 & ++ & + & + & $-1+$ & - \\
FMC7 & $-1+$ & ++ & + & + & + \\
mCD22 & - & ++ & + & + & + \\
CD10 & $-1+$ & + & + & $-1+$ & $-1+$ \\
\hline
\end{tabular}

$>75 \%$ of cases positive, $++; 25-75 \%$ of cases positive; $+; 10-25 \%$ of cases positive, $-1+$; $>75 \%$ of cases positive, $++; 25-75 \%$ of cases positive; $+; 10-25 \%$ of cases positive, $-/+$;
$<10 \%$ of cases positive, - ; FL, follicular lymphoma; MCL, mantle cell lymphoma; LCL, large $<10 \%$ of cases posi
cell lymphoma. follicular so that the Kiel category of centroblastic/centrocytic lymphoma is largely synonymous with follicular lymphoma. A significant minority of cases have circulating lymphoma cells at diagnosis and others develop a leukaemic phase during the course of the illness (table 1). ${ }^{57910}$ Bone marrow infiltration is present in a larger number. ${ }^{71}$ The lymphocyte count varies from moderately elevated to very high levels. Circulating neoplastic lymphocytes can also be recognised in some patients without lymphocytosis, perhaps as many again as those who have circulating lymphoma cells with lymphocytosis. ${ }^{9}$ Cytological features vary. In many cases the lymphocytes are very small, conspicuously smaller than CLL cells. They have scanty weakly basophilic cytoplasm, a homogeneous chromatin pattern, notched or cleft nuclei, and an angular rather than rounded cellular outline. These cytological features are particularly characteristic of cases with a very high lymphocyte count. ${ }^{23}$ In other cases cells are larger and somewhat pleomorphic with some having small but obvious nucleoli or deep nuclear clefts with parallel edges. Presentation in leukaemic phase has not generally been found to be of prognostic significance. ${ }^{5710}$ However, heavy bone marrow infiltration correlates with a shorter survival ${ }^{24}$ and cases presenting with a high white cell count (greater than $50 \times 10^{9} / 1$ ) also generally have widespread disease and tend to have a short survival. In a small subset of cases in which cells appear more blastic, both on histological sections and in the blood, the development of a leukaemic phase has been indicative of short survival. ${ }^{5}$ The presence of circulating large lymphoma cells in a patient with follicular lymphoma is indicative of transformation and of a poor prognosis.

The differential diagnosis of the leukaemic phase of follicular lymphoma is with CLL, from which a distinction can be made on the basis of cytology and immunophenotype (table 2), and with mantle cell lymphoma (see later). A provisional diagnosis of follicular lymphoma can be confirmed by cytogenetic or DNA analysis as at least $80 \%$ of cases show a characteristic translocation, $t(14 ; 18)(\mathrm{q} 32 ; \mathrm{q} 21)$, with the consequent juxtaposition of $b c l-2$ and the immunoglobulin heavy chain gene. In addition, DNA analysis reveals that there are small numbers of circulating cells with this translocation in most patients with follicular lymphoma, even when no cytologically abnormal cells can be detected in the peripheral blood, and in apparently early stage disease. ${ }^{25}$

MANTLE CELL LYMPHOMA

Mantle cell lymphoma is now the preferred designation for the subtype of lymphoma classified by the Kiel group as diffuse centrocytic lymphoma ${ }^{1}$ and by others as malignant lymphoma of intermediate differentiation. ${ }^{26}$ Bone marrow and peripheral blood involvement are common (table 1). ${ }^{12-18}$ The condition has been confused with CLL when a lymph node biopsy has not been performed ${ }^{27}$ but in our experience cases differ cytologically as well as immunophenotypically. ${ }^{27}$ Lymphoma cells are lar- 
ger and more pleomorphic than those of CLL. They vary from small to medium in size with a variable amount of cytoplasm. Some cases have medium sized and large cells. The chromatin pattern varies from condensed to diffuse with some cells having nucleoli which may be prominent. Nuclei vary in shape from round to angular, irregular or deeply clefted. Confusion with follicular lymphoma can occur but in general the cells of mantle cell lymphoma are larger and more pleomorphic. The immunophenotype permits a ready distinction from CLL but not so readily from follicular lymphoma (table 2). However, mantle cell lymphoma is more likely than follicular lymphoma to be CD5 positive and less likely to be CD10 positive (table 2). Cytogenetic and DNA analysis can confirm a provisional diagnosis as the $t(11$; 14) (q13;q32) translocation is present in more than $50 \%$ of cases.

Most patients with mantle cell lymphoma have advanced stage disease at presentation and in general neither bone marrow nor peripheral blood involvement has been found to be of prognostic significance. However, in those patients with a mantle zone pattern of infiltration, in whom the overall prognosis is better, a significant difference in survival has been found between those with and without a leukaemic phase. ${ }^{17}$

\section{MONOCYTOID B CELL LYMPHOMA}

Monocytoid B cell lymphoma is a recently recognised clinicopathological entity which is not specifically identified in the Kiel classification. Bone marrow infiltration is uncommon and a leukaemic phase is rare (table 1). Cytological features of circulating lymphoma cells have varied between cases from moderately sized cells with round to reniform nuclei and abundant weakly basophilic cytoplasm to relatively homogeneous small cells with nuclear notches, grooves and creases, and scanty cytoplasm. ${ }^{28-30}$ Some cases show plasmacytoid differentiation. ${ }^{28}$ The differential diagnosis of monocytoid B cell lymphoma includes mantle cell lymphoma. Immunophenotype may be of use in diagnosis as in most cases cells are negative for CD5 and CD10 but express CD11c. No characteristic cytogenetic abnormality has been identified in this lymphoma. Peripheral blood and bone marrow involvement have been associated with a poor prognosis. ${ }^{30}$

\section{MALT LYMPHOMA}

The mucosa associated lymphoid tissue (MALT) lymphoma is another recently identified entity. Its natural history is to remain localised to the gut or other mucosal tissues for long periods of time. Bone marrow infiltration has been found in only 1 to $2 \%$ of cases and peripheral blood involvement is rare. In one case described in detail ${ }^{31}$ the cells were small to medium in size with round, oval or somewhat reniform nuclei and relatively abundant cytoplasm. There were also circulating plasmacytoid lymphocytes and mature plasma cells. It is obviously unlikely that this rare leukaemic presentation of MALT lymphoma would be recognised from the peripheral blood features. Mantle cell lymphoma and monocytoid B cell lymphoma would appear to be the lymphomas with which it is most likely to be confused. A poor prognosis would be expected in patients with bone marrow or peripheral blood involvement.

\section{B CELL LINEAGE LARGE CELL LYMPHOMAS}

Peripheral blood involvement by large cell lymphomas is uncommon. Centroblastic lymphoma, either occurring de novo or as a transformation of follicular lymphoma, may have a leukaemic phase but this is unusual (table 1). A leukaemic phase of immunoblastic lymphoma appears to be even less common and we have not observed leukaemia in anaplastic large cell lymphoma. It is not possible to make a reliable distinction between large cell lymphomas of different histological types on the basis of peripheral blood cytology ${ }^{32}$ nor even to distinguish $B$ cell lineage from $T$ cell lineage lymphomas. In all cases the cells are large and pleomorphic, usually with abundant moderately basophilic cytoplasm and prominent nucleoli. In some cases cells show a cytological resemblance to monoblasts so that acute monoblastic leukaemia enters into the differential diagnosis. A leukaemic phase is associated with a poor prognosis.

\section{BURKITT'S LYMPHOMA}

Burkitt's lymphoma and the L3 subtype of acute lymphoblastic leukaemia ${ }^{33}$ can be regarded as variants of a single disease. The neoplastic cells are distinctive medium sized blasts with strongly basophilic vacuolated cytoplasm. In endemic Burkitt's lymphoma a leukaemic phase occurs as a late event and is associated with a poor prognosis. A leukaemic presentation is more common in non-endemic Burkitt's lymphoma, in which it is compatible with cure of the disease as long as appropriate intensive chemotherapy is given. In AIDS related Burkitt's lymphoma bone marrow and peripheral blood involvement are common and are associated with a dismal prognosis.

\section{LYMPHOBLASTIC LYMPHOMA}

Only a minority of lymphoblastic lymphomas are of $\mathrm{B}$ cell lineage. If a leukaemic phase occurs, it is indistinguishable from L1 or L2 subtypes of B cell lineage acute lymphoblastic leukaemia (ALL).

\section{$T$ cell lineage lymphomas}

SMALL CEREBRIFORM CELL LYMPHOMA/ CUTANEOUS T CELL LYMPHOMA

Cutaneous $T$ cell lymphomas present clinically as either mycosis fungoides or Sézary's syndrome. Circulating neoplastic cells, together with erythroderma consequent on cutaneous infiltration, are essential for the diagnosis of Sézary's syndrome. Sézary cells may be in- 
frequent or very numerous. Cells may all be small or there may be a mixture of small and large cells. Cells have a highly infolded, complex nuclear form usually described as cerebriform or convoluted. The nucleus is often hyperchromatic. Cytoplasm is weakly to moderately basophilic and may be vacuolated. Lymphocyte nuclei can become cerebriform following cellular activation ${ }^{34}$ and small Sézary cells can thus be difficult to distinguish from reactive lymphocytes. Up to $15 \%$ of such cells have been observed in patients with non-neoplastic skin conditions and occasional similar cells can be found in healthy individuals. Large Sézary cells are more obviously neoplastic. If circulating neoplastic cells are present in mycosis fungoides they have the same cytological features as Sézary cells. Cytogenetic analysis and demonstration of aneuploidy by flow cytometric quantification of DNA are useful for detecting peripheral blood involvement in cutaneous $\mathrm{T}$ cell lymphomas. Ultrastructural examination can also be useful if the characteristic nuclear form cannot be identified by light microscopy. Overall, circulating neoplastic cells have been found in $18 \%$ of cutaneous lymphomas at presentation and in another $43 \%$ during the course of the disease. ${ }^{34}$ Detection of Sézary cells has sometimes permitted a diagnosis of Sézary's syndrome when skin biopsies have been non-specific. ${ }^{34}$ Occasional patients present with a Sézary cell leukaemia without cutaneous manifestations, although skin infiltration may develop as a late event.

In mycosis fungoides circulating lymphoma cells are uncommon; the likelihood of leukaemia is related to the extent of cutaneous disease, being greater when there are generalised rather than limited plaques and greater still when there is tumour formation. ${ }^{35}$ In cutaneous $T$ cell lymphomas the presence of small Sézary cells in the peripheral blood is not necessarily of prognostic significance but the presence of absolute lymphocytosis, ${ }^{35}$ of more than $20 \%$ of Sézary cells ${ }^{35}$ or of a high percentage or increased absolute count of large Sézary cells, is indicative of a poor prognosis. ${ }^{3435}$

\section{PERIPHERAL T CELL LYMPHOMAS}

The Kiel classification includes a number of lymphomas of mature peripheral $T$ cells and although they often infiltrate the bone marrow to a greater or lesser extent there is rarely leukaemia. When circulating neoplastic cells are present they do not have any distinctive features which permit their distinction from each other or indeed from B cell lymphomas. The only exception is adult $\mathrm{T}$ cell leukaemia/ lymphoma (see later). Some peripheral T cell lymphomas have predominantly small cells (lymphoepithelioid (Lennert's) lymphoma, angioimmunoblastic lymphoma, $T$ zone lymphoma and pleomorphic small cell lymphoma). When they have a leukaemic phase the cells tend to be small to medium in size and moderately pleomorphic. Other peripheral $\mathrm{T}$ cell lymphomas have predominantly large cells (pleomorphic medium and large cell lymph- oma, immunoblastic large cell lymphoma and anaplastic large cell lymphoma). Any leukaemic cells are large and pleomorphic with moderately abundant, often strongly basophilic cytoplasm and prominent nucleoli. Immunophenotyping permits the diagnosis of a $\mathrm{T}$ cell lymphoma, although the phenotype is often aberrant with failure to express some of the antigens which are normally expressed on mature T cells. ${ }^{33}$

\section{ADULT T CELL LEUKAEMIA/LYMPHOMA}

About $80 \%$ of cases of adult $\mathrm{T}$ cell leukaemia/ lymphoma associated with the human $\mathrm{T}$ cell lymphotrophic virus I (HTVL-I) present with leukaemia. The diagnosis is usually readily made from the cytological features. Cells are very pleomorphic with a mixture of small, medium and large cells. Many of the nuclei are lobulated, with some having multiple lobes so the nuclear shape resembles a flower. A minority of cells have convoluted nuclei and thus resemble Sézary cells. The chromatin pattern varies from cell to cell. Some cells may have hyperchromatic nuclei while others have a diffuse chromatin pattern and resemble blasts. Some cells are nucleolated.

The differential diagnosis is with other types of peripheral $\mathrm{T}$ cell lymphoma and with Sézary's syndrome. Immunophenotyping is useful for diagnosis as most cases are CD25 positive. The presence of hypercalcaemia provides useful indirect evidence supporting the diagnosis as it is commonly present in adult $\mathrm{T}$ cell leukaemia/lymphoma but not in other $\mathrm{T}$ cell lymphomas. Positive serology for HTLV-I can provide confirmation of the diagnosis in a patient with typical cytological features, although it should not be forgotten that patients who are seropositive will occasionally develop unrelated lymphomas or leukaemias.

\section{T LYMPHOBLASTIC LYMPHOMA}

Lymphoblastic lymphoma is more often of $\mathrm{T}$ cell lineage than of $B$ cell lineage. When a leukaemic phase occurs the cytological features are identical to those of $\mathrm{T}$ cell lineage ALL. The immunophenotype of the two diseases is very similar so that individual cases of $\mathrm{T}$ lymphoblastic lymphoma cannot be distinguished from T-ALL on this basis. The distinction is made on the percentage of bone marrow lymphoblasts at presentation, cases with more than 25 to $30 \%$ blasts being classified as T-ALL. The expression of terminal nucleotidyl transferase in $\mathrm{T}$ lymphoblastic lymphoma is of use when distinguishing it from other $T$ cell lineage non-Hodgkin's lymphomas.

\section{Conclusion}

A leukaemic phase is common in non-Hodgkin's lymphoma, particularly in low grade lymphomas. Careful cytological and immunological assessment of circulating lymphoma cells can permit a provisional diagnosis. Peripheral blood lymphoma cells can also be studied by cytogenetic and DNA analysis which can contribute to a precise diagnosis even in 
cases where there is no tissue available for a histological diagnosis. In some, but not all, subtypes of lymphoma the occurrence of a leukaemic phase is also of prognostic significance.

1 Stansfeld AG, Diebold J, Kapanci Y, Kelényi G, Lenner $\mathrm{K}$, Mioduszewska $\mathrm{O}$, et al. Updated Kiel classification for K, Mioduszewska O, et al. Updated

2 Bennett JM, Catovsky D, Daniel M-T, Flandrin G, Galton DAG, Gralnick HR, et al. Proposals for the classification of chronic (mature) B and T lymphoid leukaemias. $\mathcal{f}$ Clin Pathol 1989;42:567-84.

3 Pangalis GA, Nathwani BN, Rappaport H. Malignan lymphoma, well differentiated lymphocytic: its relationship with chronic lymphocytic leukemia and macroglobulinemia of Waldenström. Cancer 1977;39: 999-1010.

4 Morrison WH, Hoppe TR, Weiss LM, Picozzi VJ, Horning SJ. Small lymphocytic lymphoma. F Clin Oncol 1989;7: 598-606.

5 Come SE, Jaffe ES, Andersen JC, Manna RB, Johnson BL de Vita VT, et al. Non-Hodgkin's lymphoma in leukemic
phase: clinicopathologic correlations. Am $\mathcal{F}$ Med 1980;69: phase: clinic

6 Bartl R, Frisch B, Mahl G, Burkhardt R, Fateh-Moghadam $\mathrm{A}$, Pappenberger R, et al. Bone marrow histology in Waldenström's macroglobulinaemia: clinical relevance of subtype recognition. Scand $\mathcal{F}$ Haematol 1983;31:359-75.

7 Mazza P, Gherlinzoni F, Kemna G, Poletti G, Zinzani PL, Verlicchi F, et al. Clinicopathological study of nonHodgkin's lymphoma. Haematologica 1987;72:351-7.

8 Lennert K, Tamm I, Wacker H-H. Histopathology and immunocytochemistry of lymph node biopsies in chronic lymphocytic leukemia and immunocytoma. Leuk Lymphoma 1991;5 (Suppl):157-60.

9 Rappaport H, Winter WJ, Hicks EB. Follicular lymphoma: a re-evaluation of its position in the scheme of malignant a re-evaluation of its position in the scheme of malignant
lymphoma, based on a survey of 253 cases. Cancer 1956; lymphoma,

10 Spiro S, Galton DA, Wiltshaw E, Lohmann RC. Follicula lymphoma. A survey of 75 cases with special reference to the syndrome resembling chronic lymphocytic leukaemia. Br f Cancer 1975;31 (Suppl II):60-72.

11 Gallagher CJ, Gregory WM, Jones AE, Stansfeld AG, Richards MA, Dhaliwal HS, et al. Follicular lymphoma: prognostic factors for response and survival. f Clin Oncol 1986; 4:1470-80.

12 Weisenburger DD, Nathwani BN, Diamond LW, Winber CD, Rappaport H. Malignant lymphoma, intermediate lymphocytic type: a clinicopathologic study of 42 cases. lymphocytic type: a clinicop

13 Swerdlow SH, Habeshaw JA, Murray LJ, Dhaliwal HS Lister TA, Stansfeld AG. Centrocytic lymphoma: a distinct clinicopathologic and immunologic entity. Am $\mathcal{F}$ Patho 1983;113:181-97.

14 Jaffe ES, Bookman MA, Longo DL. Lymphocytic lymphoma of intermediate differentiation - mantle zone lymphoma: a distinct subtype of B-cell lymphoma. Hum Pathol 1987;18:877-80.

15 Meusers $\mathrm{P}$, Engelhard M, Bartels $\mathrm{H}$, Binder T, Fülle $\mathrm{HH}$ Görg K, et al. Multicentre randomized therapeutic trial for advanced centrocytic lymphoma: anthracycline does not improve the prognosis. Hematol Oncol 1989;7:365-80.

16 Duggan MJ, Weisenburgher DD, Ye YL, Bast MA, Pierson Duggan MJ, Weisenburgher DD, Ye YL, Bast MA, Pierson pathological study of 22 cases. Cancer 1990;66:522-9.
17 Perry DA, Bast MA, Armitage JO, Weisenburger DD Diffuse intermediate lymphoma: a clinicopathological study and comparison with small lymphocytic lymphoma Cancer 1990;66:1995-2000.

18 Zucca E, Fontana S, Roggero E, Pendrinis E, Pampallona $S$, Cavalli F. Treatment and prognosis of centrocytic (mantle cell) lymphoma: a retrospective analysis of twentysix patients treated in one institution. Leuk Lymphoma six patients treated

19 Shin SS, Sheibani K. Monocytoid B-cell lymphoma. Am $\mathcal{f}$ Clin Pathol 1993;99:421-5.

20 Isaacson PG, Matutes E, Burke M, Catovsky D. The histopathology of splenic lymphoma with villous lymphocytes. Blood 1994;84:3828-34.

21 Matutes E, Morilla R, Owusu-Ankomah K, Houlihan A, Catovsky $\mathrm{D}$. The immunophenotype of splenic lymphoma with villous lymphocytes and its relevance in the differential diagnosis with other B-cell disorders. Blood 1994; 83:1558-62.

22 Oscier DG, Matutes E, Gardiner A, Glide S, Mould S, Brito-Babapulle V, et al. Cytogenetic studies in splenic lymphoma with villous lymphocytes. Br f Haematol 1993; 85:487-91.

23 Melo JV, Robinson DSF, de Oliviera MP, Thompson IW, Lampert IA, Ng JP, et al. Morphology and immunology of circulating cells in leukaemic phase of follicular lymphoma. F Clin Pathol 1988;41:951-9.

24 Romaguera JER, McLaughlin P, North L, Dixon D, Silvermintz KB, Garnsey LA, et al. Multivariate analysis of prognostic factors in Stage IV follicular low-grade lymphoma: a risk model. $\mathcal{f}$ Clin Oncol 1991;9:762-69.

25 Lambrechts AC, Hupkes PE, Dorssers LCJ, van't Veer MB. Translocation $(14 ; 18)$-positive cells are present in the circulation of the majority of patients with localized (Stage I and II) follicular non-Hodgkin's lymphoma. Blood 1993; 82:2510-16.

26 Raffeld M, Jaffe E. Bcl-1, $t(1 ; 14)$, and mantle cell-derived lymphoma. Blood 1991;78:259-63.

27 de Oliviera MSP, Jaffe ES, Catovsky D. Leukaemic phase of mantle zone (intermediate) lymphoma. $₹$ Clin Pathol of mantle zone

28 Carbone A, Gloghini A, Pinto A, Attadia V, Zagonel V, Volpe R. Monocytoid B-cell lymphoma with bone marrow and peripheral blood involvement at presentation. $A m \mathcal{F}$ Clin Pathol 1989;92:228-36.

29 Cogliatti SB, Lennert K, Hansman M-L, Zwingers TI Monocytoid B-cell lymphoma: clinical and prognostic features of 21 patients. $\mathscr{f}$ Clin Pathol 1990;43:619-25.

30 Traweek ST, Sheibani K Monocytoid B-cell lymphoma. The biologic and clinical implications of peripheral blood involvement. Am f Clin Pathol 1992;97:591-8.

31 Griesser $H$, Kaiser $U$, Augener W, Tiemann $M$, Lenner K. B-cell lymphoma of the mucosa-associated lymphatic tissue (MALT) presenting with bone marrow and peritissue (MALT) presenting with bone marrow and peri-

32 Bain BJ, Matutes E, Robinson D, Lampert AI, Brito-Babapulle V, Morilla $R$, et al. Leukaemia as a manifestation of large cell lymphoma. $\mathrm{Br} \mathcal{F}$ Haematol 1991;77:301-10.

33 Bennett JM, Catovsky D, Daniel M-T, Flandrin G, Galto DAG, Gralnick HR, et al. Proposals for the classification of the acute leukaemias (FAB cooperative group). $\mathrm{Br}$ Haematol 1976;33:451-8.

34 Vonderheid EC, Sobel EL, Nowell PC, Finan JB, Helfrich MK, Whipple DS. Diagnostic and prognostic significance of Sézary cells in the peripheral blood smears from patients with cutaneous T-cell lymphoma. Blood 1985;66:358-66.

35 Schechter GP, Sausville EA, Fischmann AB, Soehnlen F, Eddy J, Matthews M, et al. Evaluation of circulating malignant cells provides prognostic information in cutaneous T-cell lymphoma. Blood 1987;69:841-9. 